\title{
Context representations, context functions, and the parahippocampal-hippocampal system
}

\author{
Jerry W. Rudy ${ }^{1}$ \\ Department of Psychology, Center for Neuroscience, University of Colorado, Boulder, Colorado 80309, USA
}

\begin{abstract}
Psychologists and neurobiologists have a long-standing interest in understanding how the context surrounding the events of our lives is represented and how it influences our behavior. The hippocampal formation emerged very early as a major contributor to how context is represented and functions. There is a large literature examining its contribution that on the surface reveals an array of conflicting outcomes and controversy. This review reveals that these conflicts can be resolved by building Nadel and Willner's dual-process theory of context representations. Two general conclusions emerge: (1) There are two neural systems that can support context representations and functions-a neocortical system composed primarily of perirhinal and postrhinal cortices and a hippocampal system that includes perirhinal, postrhinal, entorhinal cortices, and the hippocampal formation. (2) These two systems are not equivalent-some context representations and functions are uniquely supported by the hippocampal system. These conclusions are discussed in the context of canonical ideas about the special properties of the hippocampal system that enable it to make unique contributions to memory.
\end{abstract}

Everything we experience happens somewhere. The term "context" is often used to denote this "somewhere." In the analysis of learning and memory, the context is like the setting for a stage play (Medin and Reynolds 1985). It provides the background for the real action in the drama-the main events. More importantly, as a consequence of learning and memory processes, the context often helps to select appropriate behaviors and determine the explicit and implicit content of our thoughts. Thus, it is not surprising that psychologists have a long-standing empirical and theoretical interest in understanding just what makes up a representation of context and how context representations interact with the main events of our lives to influence our behavior (see Balsam and Tomie 1985).

More recently, neurobiologists have increased their interest in the problem of linking context representations and functions to brain systems. The hippocampal formation emerged quite early as a major focal point among many researchers. As a result, there is a substantial literature linking the hippocampal formation and context. However, on the surface, this research yields a dismaying set of conflicting results, with many findings that the hippocampal formation plays a critical role in supporting the influence of context on memory and behavior and many other findings that it does not.

The goal of this article is to bring some clarity and order to this state of affairs. I start by providing a working definition of "context" that implicitly underpins its experimental analysis. I then describe several different functions of context that have been studied in the laboratory and are assumed to be theoretically important. I then introduce and build on a dual-process theory of context representations that was put forth several years ago by Lynn Nadel, Jeffrey Willner, and colleague (Nadel and Willner 1980; Nadel et al. 1985) and more recently by my colleagues and me (Rudy and O'Reilly 2001; Rudy et al. 2002). I then apply this framework to a wide range of outcomes from experiments that examined the role of the hippocampal formation in ways in which context influences memory and behavior. Two general conclu-

\footnotetext{
'Corresponding author.
}

E-mail JRudy@Clipr.Colorado.Edu; fax (303) 492-2967.

Article is online at http://www.learnmem.org/cgi/doi/10.1101//m.1494409. sions emerge from this exercise. First is that two systems can support context representations and functions: (1) a neocortical system composed primarily of perirhinal and postrhinal cortices and (2) a hippocampal system that includes parahippocampal cortices; perirhinal, postrhinal, and entorhinal cortex; and the hippocampal formation. The second is that these two systems are not equivalent-some context representations and functions are uniquely supported by the hippocampal system. These conclusions are discussed in the context of long-standing ideas about the special properties associated with the hippocampal system that support its unique contributions to memory.

\section{Definition of "context"}

A "context" must be composed of something. As a starting point, one can define its composition as "a set of concurrent independent component features that potentially can be sampled by an individual." But what constitutes the defining property of a component feature? The problem is how to answer this question without including the individual experiencing the features. A practical and useful approach is to define the features from the perspective of the experimenter as opposed to the individual in the experiment. This approach deliberately avoids reference to internal representations constructed by the subject of the experiment. From this perspective, the features that define a particular context should have two properties:

- They must be "stable," meaning that the features and their relationship to each other will be there even if no one is there to experience them. Thus, the features of my office will remain even when I leave. Nadel (2008) has offered a similar view: "Features that are relatively stable first of all define contexts" (p. 8).

- They should also be subject to "component variation," meaning that someone can remove a component or rearrange its relationship with some other component. For example, someone could remove the desk, add a white board to a wall, or move memorabilia from one wall to another, or a new occupant might remove and replace every independent feature in my office. At the end, then, a stable set of features would exist, but the office would differ from its current composition. In principle, a new 
context is created. The component variation property is important because it is only through variation of components that context can be experimentally manipulated. This framework does not speak to how much component variation needs to occur before a subject represents it as new or different from one previously experienced. This is largely an empirical question. Nor does it speak to the neural mechanisms that determine when, from the perspective of the learner, a new context has been registered. However, O'Reilly and McClelland (1994) and more recently Nadel (2008) have discussed some possibilities.

The stable property of context features can be contrasted with features that have a "phasic property," that is, features that occur in a context but are not stable. For example, my telephone might occasionally ring, but the ringing of the phone is not a stable feature of the context; it is something that happens in my office.

As another illustration, consider a simple conditioning situation where the main events are the conditioned (CS) and unconditioned (US) stimulus (the CS-US pairing). Applied to a simple conditioning experience, the context features would be floor texture, ambient lighting and sound, odors, opaqueness of the walls of the chamber, size and shape of the conditioning chamber, and so forth, any one of which can be varied by the experimenter to create another different but stable collection of features. The presentation and termination of the CS would not be a context feature because it is not stably present. It is something that happens against the stable context features.

It should be appreciated that at the level of experimental analysis everyone implicitly embraces this definition of context. This is the case because otherwise there would be no independent variables available to study how context influences memory and behavior. Nevertheless, some might find that this definition of context begs an important issue that brings the organism into the equation. Specifically, it is quite possible that some stable feature of a context can move from the background to the foreground. For example, a recent visitor to my office commented on the portrait of the famous gypsy jazz guitarist Django Reinhardt that is a stable feature of my office. This changed the status of this feature from being part of the background to being in the foreground. It became part of an episode that occurred against the contextual background in much the same way that the telephone rings or a colleague enters my office.

\section{Some functions of context representations}

Perhaps the most fundamental problem one must appreciate in linking context to brain systems is that the term "context" is used to describe a variety of tasks that make quite different demands on learning and memory processes. The problem emerges because the properties of the task likely determine which neural systems are engaged to support the outcome of the experiment. Thus, to lay the foundation for this linkage, it is important to describe a number of important functions served by context representations. Some of the key findings and ideas have emerged from studies of simple and complex conditioning experiments (see Balsam 1985). Others have emerged from empirical and theoretical analyses outside of the conditioning tradition.

\section{Association and competition}

From a learning and memory perspective, researchers who study Pavlovian conditioning are often interested in understanding the associative structures produced as a consequence of CS-US pairings that contribute to the later retrieval of the representation of the unconditioned stimulus and/or the conditioned response. In some theories, component context features have the same status as the phasic CS (e.g., Rescorla and Wagner 1972). In such accounts, context features can both associate with the US and compete with the CS for associative strength supported by the US; that is, associative strength captured by context features will come at the expense of what can be captured by the other features.

There is no doubt that a context representation can associate with the representation of the US. For example, there are dozens of reports that rats will display an innate defensive freezing response when placed into a conditioning context in which they were previously shocked (see Rudy et al. 2002; Sanders et al. 2003). Canonical empirical support for the idea that cues compete for association with the US comes from what is called the "blocking effect" discovered by Kamin (1969). He reported that prior conditioning to one component (e.g., tone-US) of a compound (light + tone) CS blocked conditioning to the other element when the light + tone compound was paired with the US. This result was interpreted to mean that the tone had acquired the available associative strength supported by the US, leaving little or none to be captured by the light.

There is also evidence that the context can compete with the CS for associative strength. For example, several sessions of fear conditioning in which just the shock US is presented in the conditioning context will block subsequent conditioning to a phasic CS subsequently paired with shock in that context (e.g., Ayres et al. 1985; Randich and Ross 1985).

\section{Incidental learning}

In most conditioning situations, the primary focus is on the conditioning that occurs to the CS paired with the US. In such situations, the context is stable at the time of training. In this case, the context is described as incidental to the learning initiated by the CS-US pairing, meaning that, in principle, learning about the context is unnecessary for the animal to learn the CS-US relationship. Nevertheless, rats not only learn the CS-US association, but they also remember where the learning occurred (Penick and Solomon 1991; Honey and Good 1993; Good et al. 1998). For example, Good et al. (1998) trained rats to learn that in context A, CS1 was followed by a food pellet, and that in context B, CS2 was followed by the pellet. That rats learned where the conditioning occurred was revealed when they were tested with CS1 in context $\mathrm{B}$ and CS2 in context A. In both cases, rats' conditioned responding was reduced when the CS was presented in a different context. Latent inhibition (Lubow 1973) provides another example of incidental context learning. In this case, subjects are exposed to the CS prior to conditioning. Latent inhibition is then revealed when the pre-exposed subjects condition more slowly to the CS than non-pre-exposed subjects. However, if there is a context shift between pre-exposure and conditioning, then latent inhibition is greatly reduced. This indicates that the rats have learned where they were exposed to the CS (Hall and Minor 1984; Holt and Maren 1999).

\section{Disambiguation function}

Context provides a place for the main events of our lives. It also can provide a basis for interpreting the meaning of a particular event-how one should react to it. For example, consider hearing someone yell "Fire!" One should behave quite differently to this stimulus if it is experienced in a movie theater or restaurant than if it is experienced at a local rifle range. The stimulus "Fire!" is ambiguous - it has more than one meaning. The function of the context in this case is to disambiguate the meaning of the event "fire."

\section{Conditional discriminations}

There is a substantial literature documenting this disambiguating function of context. Somewhat more complex conditional discrimination learning procedures have been used for this purpose. 
For example, in context A, cue 1 signals a forthcoming reward, but cue 2 signals no reward (A: $\mathrm{C} 1+, \mathrm{C} 2-$ ). However, in context $\mathrm{B}$, the contingencies are reversed, with cue 2 signaling reward and cue 1 signaling no reward (B: $\mathrm{C} 1-, \mathrm{C} 2+)$. Note that $\mathrm{C} 1$ and $\mathrm{C} 2$ are completely ambiguous-they equally often signal reward and no reward. An individual insensitive to the context would be completely baffled as to how to respond to them. Nevertheless, it is well established that rodents, dogs, and pigeons can solve this class of discriminations (Wyrwicka 1956; Thomas 1985; Good et al. 1998). Thus, these results indicate that animals can learn to use the training context to specify the meaning of otherwise ambiguous cues.

\section{Context-specific extinction}

Recently, the phenomenon known as "extinction"- "the loss of a conditioned response to a CS that is produced when the CS is repeatedly presented alone"-has attracted the attention of many researchers. Moreover, this modern literature has revealed that the context plays an important disambiguation role in extinction (Bouton 1993, 2004). This is because many experiments have revealed that the procedure of extinction does not erase the existing associations that produce the conditioned response. Instead, the contemporary view holds that the consequence of CS-US pairings is the production of a CS-US association and the consequence of CS-alone presentations (extinction) is the production of a CS-no US association. Extinction by this view produces new learning. Since after extinction both associations are potentially available to influence behavior, the meaning of the CS is ambiguous (Bouton 1993, 2004).

The research of Bouton and others (e.g., Bouton and Bolles 1979; Bouton 1993, 2004; Corcoran and Maren 2004; Ji and Maren 2007) has revealed that the context makes an important contribution to determining how the individual will respond to such an ambiguous CS. The most robust example comes from a result called the "renewal effect" (Bouton 1993, 2004). This result is revealed in two ways: In one case, an ABA design is used (where $\mathrm{A}$ and $\mathrm{B}$ designate different contexts), conditioning (CS-US pairings) occurs in one context, $\mathrm{A}$, and extinction (CS-alone presentations) occurs in a different context, $\mathrm{B}$. If the individual is then retested in context $A$, the conditioned response reappears. In the second case, an $\mathrm{ABC}$ design is used. The primary difference is that the test for the extinction takes place by presenting the CS in a third context, C. Again, the conditioned response to the CS is renewed. An intuitive account of these results is that during extinction, the individual learns that in context B the CS is no longer followed by the US. Extinction is thus specific to the context in which CS-alone presentations were experienced. Thus, when the CS is tested outside of the extinction context, B, the original CS-US association controls behavior. Context-specific extinction might also be considered to be an example of incidental context learning because the primary outcome of interestextinction of responding to the CS-does not require learning about the context.

\section{Acquiring a context representation}

Before a context can provide the setting for an event(s) or can be used to disambiguate the meaning of some other feature, its representation must be established. Fanselow (1990) introduced a powerful methodology for investigating the acquisition and retrieval of context representation called the "context pre-exposure facilitation effect" (see Fig. 1). It takes advantage of a phenomenon in the fear-conditioning literature called "the immediate shock effect." If a rat is shocked very shortly $(2-3 \mathrm{sec})$ after it is placed into a conditioning chamber, it will later display little or no fear of that conditioning context. In contrast, the amount of conditioning increases dramatically if the rat is allowed to explore

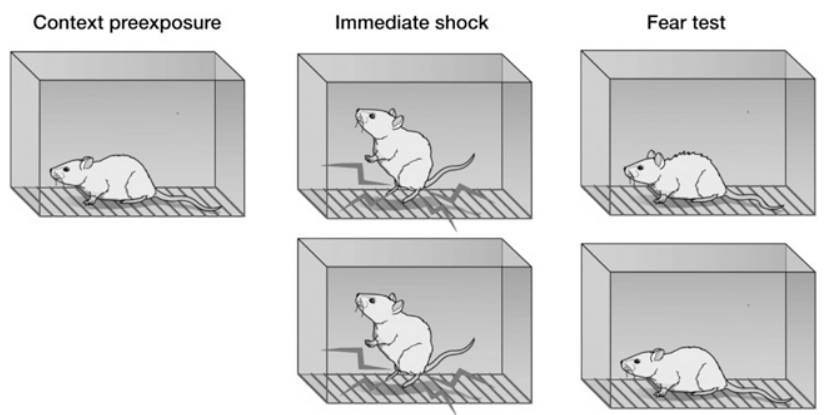

Figure 1. This cartoon illustrates the context pre-exposure facilitation effect discovered by Fanselow (1990). When rats are immediately shocked, they display very little fear of the context. However, if they are pre-exposed to the context, they display fear of that context. (Figure is from Rudy [2008], and reprinted with permission from Sinauer Associates (C2008.)

the conditioning chamber for about 30 sec. Fanselow (1990) discovered that rats who were allowed to explore the conditioning chamber the day before the immediate shock experience displayed substantial fear to that context. He proposed that the context preexposure experience established a context representation that could be retrieved by a subsequent brief exposure to the context prior to the shock. The context pre-exposure facilitation effect has been reported numerous times (e.g., Ayres et al. 1985; Rudy and Morledge 1994; Westbrook et al. 1994; Rudy et al. 2002; Stote and Fanselow 2004; Rudy and Wright-Hardesty 2005).

\section{Objects in context}

Contexts provide a place for experience. Context also provides a place where things are located. Studies based on what is called "object recognition" have provided evidence that rodents not only can recognize previously experienced objects; they also know where the object was experienced (e.g., Dellu et al. 1997; Dix and Aggleton 1999). The basic paradigm is illustrated in Figure 2. A rat is exposed to two identical objects (cubes) in one context and two other identical objects (cylinders) in a second context. During a test, the experimenter places a single copy of each object in both contexts and the rat is allowed to explore them for a brief period of time. Such tests reveal that the rat spends more time investigating the object new to the test context than the object that was experienced previously in that context. This means that the rat established a representation of the two contexts and remembers the context in which the objects were initially encountered.

\section{Episodic memory and context}

Most memory researchers accept the position that there is an episodic memory system (Tulving 2002) designed to store the events of our life in a way that permits us to later consciously recollect the experience. Another important property of this system is that it appears to automatically capture a record of daily events without any intent on our part to do so. For example, it is likely that you can answer the question, what did you have for lunch yesterday? If you were subsequently asked if you intended to remember this experience, your likely answer would be no.

Context also is thought to play a special role in the recall of episodes. Several researchers agree that the feeling of remembering emerges when a retrieved memory trace contains information about the time, place, or context of the experience that established the memory (e.g., Nadel and Moscovitch 1997; Squire and Kandel 1999; Tulving 2002). In describing the importance of contextual information to recollection, for example, Squire and Kandel (1999) wrote, "Once the context is reconstructed, it may seem 
(A) Exploration

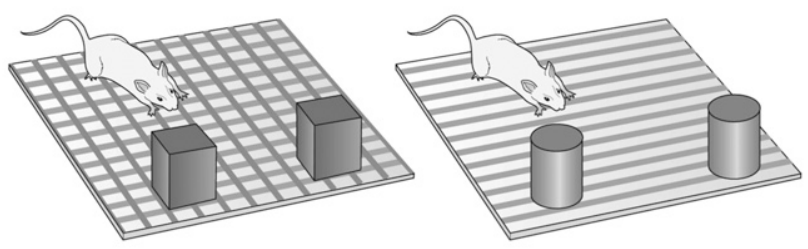

(B) Test

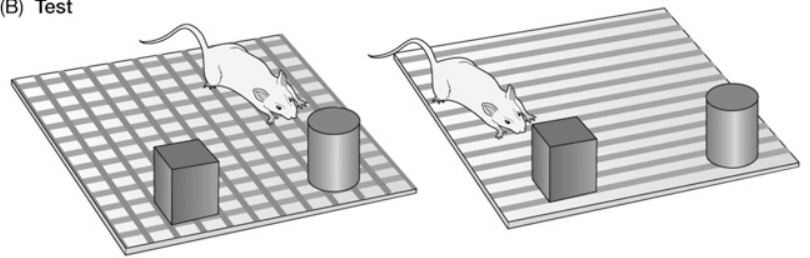

Figure 2. Illustration of the object-in-context procedure. $(A)$ In the exploration phase, rats are allowed to explore and sample two objects, a cube and a cylinder. Two cubes were present in one context, and two cylinders were present in the other context. $(B)$ During the test phase, the cube and the cylinder are in each context. Normal rats spent more time exploring the object that had not previously been presented in the test context, indicating a memory for where the object had been previously experienced. (Figure is from Rudy [2008], and reprinted with permission from Sinauer Associates (C)2008.)

surprising how easy it is to recall the scene and what took place. In this way, one can become immersed in sustained recollection, sometimes accompanied by strong emotions and by a compelling sense of personal familiarity with what is remembered." Embedded in this thinking is the idea that part of what is required to remember a past event is the activation of a coherent representation of the context in which the event was experienced.

\section{Dual-systems theory of context representations}

Having described some of the primary functions context can play in the control of behavior, it is time to address how these observations might relate to theories of context and brain systems. Many researchers believe that the hippocampal formation makes a critical contribution to contextual control over behavior. This idea first emerged $35 \mathrm{yr}$ ago when Hirsh $(1974,1980)$ proposed that the hippocampal formation is critical to what is referred to above as the "disambiguation function of context."

However, it was shortly thereafter that Nadel, Willner, and others (Nadel and Willner 1980; Nadel et al. 1985; see also Nadel 2008) provided a more general view of how the brain supports context functions. Their framework was built around two ideas. First, they proposed a dual-representation view of context (Fig. 3). One representation is the classic elemental associative account (e.g., Rescorla and Wagner 1972). Experience establishes representations of individual context features, and each feature can associate with the representation of some other event (such as the CS or the US). In such accounts the associative strengths of the individual features summate to retrieve the representation of the event.

Nadel and Willner called the second category a "hierarchical representation" and assumed that co-occurring separate context features are bound together to form a new representation that function as a unit. Once individual features are bound into a coherent hierarchical representation, an experienced event will be represented as occurring in a particular place even though the organism might register only a subset of context features at the time of the experience. In contrast, strictly elemental association accounts of context would only link the event representation to the representations of the individual context features registered at the time the event occurred. Slight variations on Nadel and Willner's dual representation view can be found in other accounts (Rudy and O'Reilly 2001; Rudy et al. 2002).

Nadel and Willner's second proposal tied these two types of context representations to different neural systems. Specifically, they proposed that neocortical regions that did not include the hippocampal formation supported elemental/feature representations but that a neural system that included the hippocampal formation was needed to support hierarchical representations.

It should be appreciated that this dual-process view of context representations implies the possibility that the hippocampal formation is not essential for all context functions. This turns out to be the case. The evidence reviewed below indicates that some context functions require the hippocampal formation but that others can be carried out by a neocortical system that does not include the hippocampal formation. However, before making this case, it is useful to describe the organization of the neural system that contains the hippocampal formation.

\section{The parahippocampal-hippocampal system}

Lavenex and Amaral (2000) describe the hippocampal formation as situated in a neural system organized around two principles. First, the organization is "hierarchical" - the information the hippocampal formation receives becomes increasingly well integrated as it flows from neocortical associative areas to parahippocampal regions that surround the hippocampal formation. Information that starts out as widely distributed patterns of neural activity in the neocortex converges onto fewer regions. Second, the system has a loop-like organization in which there are reciprocal connections so that information processed in a downstream receiving region is projected back to the sending region. Because it receives information distributed over multiple brain regions, the hippocampal formation is positioned to see what is happening all over the neocortex and has been described by O'Keefe and Nadel (1978) as providing an ongoing map of Euclidian Space and by Teyler and DiScenna (1986) (see also Teyler and Rudy 2007) as providing a map of cortical space. Thus, the hippocampal formation is anatomically positioned to support context representations, and this has been amply documented (see Smith and Mizumori 2006a,b).

Following the nomenclature of Furtak et al. (2007), the hippocampal formation consists of the hippocampal formation proper, which is composed of three subdivisions: CA3, CA2, and CA1; the dentate gyrus; and the subiculum. In primates the areas surrounding the hippocampal formation include the entorhinal, peririhinal, ectorhinal, and parahippocampal gyrus, term TF, and TH. Most of
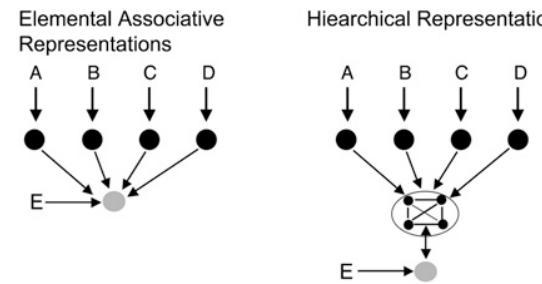

Figure 3. Illustration of the dual systems theory of context representations. The elemental association account assumes that the context is represented as a set of individual features (A-D) that independently associate with some event (E). The neocortex is assumed to support elemental context representations. The hierarchical view assumes that the individual elements or features of a context are bound into a representation that functions as a unit to define a place where an event occurs. Hierarchical representations require the hippocampal formation for support. 
the analytic studies relating the behavioral functions of context to the brain, however, use rodents. Furtak et al. (2007) have designated the critical surrounding areas in the rodent brain as the perirhinal (PER), postrhinal (POR), and entorhinal cortices (EC), and suggested that POR has connectional homology with primate parahippocampus (see also Burwell and Amaral 1998a,b; Burwell 2000; van Strein et al. 2009). They also provided many details of the connections to and from these regions. For the remainder of this article, I refer to this collection of brain regions as the "hippocampal system" (HS). A highly schematic illustration of these general ideas is presented in Figure 4. The interested reader can consult several excellent reviews that describe the detailed connections among these regions (e.g., Burwell and Amaral 1998a,b; Burwell 2000; Furtak et al. 2007; van Strein et al. 2009).

Two neural systems support context representations As noted earlier, an important implication of the dual-process theory of context is that not all context functions depend on the hippocampal system. The surrounding cortices might support some functions in the absence of a functional hippocampal formation. In this section, I summarize some of the important findings relating the components of the hippocampal and neocortical systems to context functions.

\section{Contextual fear conditioning}

The contextual fear-conditioning paradigm is an often-used procedure for studying the influence context. Slight variations of the basic procedure used in combination with methods for damaging or inactivating regions of the hippocampal system have yielded important support for the dual-systems view and some insight into some of the differences between the two systems. In the typical experiment, a rodent (rat or mouse) is placed into a conditioning chamber for some period of time, usually a minute or two, and then shocked. Sometime later the rat is returned to that context and tested several minutes for its fear of the "conditioning context." The usual dependent variable is the time the rat spends freezing, a naturally occurring defensive response to threat (Blanchard et al. 1976).

It is often stated that contextual fear conditioning depends on the hippocampal formation. However, without qualification, this statement is false (Ji and Maren 2007; Biedenkapp and Rudy

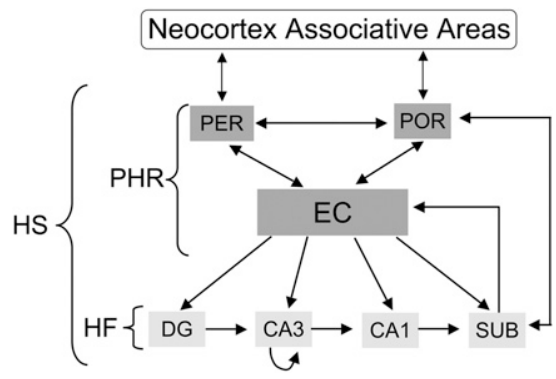

Figure 4. A highly schematic illustration of the components of the parahippocampal-hippocampal system (HS) and connections among them. Information is increasingly integrated as it flows from the neocortical associative areas to the parahippocampal regions and the hippocampal formation. The organization of this system also features reciprocal connections with multiple return loops so that information processed in a downstream receiving region is projected back to the sending regions. The hippocampal formation sits at the top of this hierarchical arrangement. (DG) Dentate gyrus; (SUB) subiculum; (EC) entorhinal cortex; (PER) perirhinal cortex; (POR) postrhinal cortex; (PHR) parahippocampal region; (HF) hippocampal formation.
2009); the literature reveals that the validity of this statement depends on several factors. One important factor is the anterograde-retrograde dimension-whether some component of the hippocampal formation is damaged or inactivated before or after training. It is clear that extensive damage to the hippocampal formation before conditioning only has a minor influence on contextual fear conditioning (Maren et al. 1997; Frankland et al. 1998; Cho et al. 1999; Richmond et al. 1999; Wiltgen et al. 2006; Biedenkapp and Rudy 2009). Given this result, one has to conclude that there is a neural system that does not contain the hippocampal formation that can support a context representation able to associate with shock. In fact, if only the anterograde data were available, there would be little reason to believe that the hippocampal formation is involved in contextual fear conditioning. However, studies using a retrograde procedure reveal a different outcome-damage to the hippocampal formation after conditioning can almost completely eliminate contextual fear conditioning (Maren et al. 1997; Maren 1999; Wiltgen et al. 2006; Lehmann et al. 2007, 2009; Sutherland et al. 2008; Biedenkapp and Rudy 2009).

The implications of the combined anterograde and retrograde contextual fear literature are clear. There are two neural systems that can support context representations capable of associating with shock-a system that includes the hippocampal formation and one that does not. These data also have an important theoretical implication that was first noted by Maren et al. (1997). Specifically, they noted that such results not only imply two neural systems that can support contextual fear conditioning, but they also imply that there is competition between them for control over fear. Moreover, in the intact animal, the system containing the hippocampal formation normally dominates the other system. This competition hypothesis provides a reasonable account of the data. If the hippocampal formation is damaged prior to conditioning, then the other system will be able to acquire control over the fear system and generate a fear response at the time of testing. However, if the hippocampal formation is functional during conditioning, it will (1) acquire control of the fear system and (2) prevent the acquisition of control by the other system. Thus, if the hippocampal formation is damaged after conditioning, the expression of contextual fear will be impaired because the information that was acquired by the hippocampal system will not be available, and the other system never acquired the relevant information.

I have emphasized that the anterograde-retrograde dimension is a critical determiner of the effect of damage to the hippocampal formation on contextual fear conditioning. It is interesting to note, however, that this dimension also is critical to the results obtained with other tasks. For example, Epp et al. (2008) reported that rats with damage to the hippocampus are not impaired in learning two-choice picture discriminations. Yet, damage to the hippocampus following acquisition causes retrograde amnesia. A similar pattern of results also exists in the impact of hippocampal formation damage on the visible platform version of the water maze (for review, see Sutherland et al. 2001). Such results add support to the conclusion that the intact hippocampal system tends to dominate extrahippocampal systems in the competition for control over behavior.

A second factor that determines if contextual fear conditioning is dependent on the hippocampal system is the training parameters. As noted, many studies have reported that damaging the hippocampal formation after training severely impairs contextual fear. A common feature of these studies is that the rodents only received a single fear-conditioning session, often with multiple shock presentations within the session. Recently, Lehmann et al. (2009) replicated the results obtained with a single sessionsevere retrograde amnesia. However, they also reported that if these 
shocks are distributed across multiple sessions, then subsequent damage to the hippocampal formation does not impair the rat's fear of the context.

The single-session data thus support the idea that the hippocampal system dominates the other system, but the multiplesession results also indicate that this dominance can be overcome when the shocks are distributed across sessions. Thus, the results with distributed contextual fear-conditioning sessions also imply that another neural system that does not include the hippocampal formation also can support contextual fear conditioning.

\section{Defining the neocortical system}

What are the components of the "other" system that can support contextual fear in the absence of the hippocampal formation? There are several reasons for believing that in the rat, the perirhinal and postrhinal cortices may be key components of the neocortical system that can support contextual fear conditioning when the hippocampal formation is removed prior to conditioning:

- These cortices receive information from other cortical areas and carry it forward primarily via entorhinal cortex to the hippocampal formation, providing it with the highly processed information it needs to support context representations and functions (Eichenbaum 2000; Lavenex and Amaral 2000; Furtak et al. 2007; van Strien et al. 2009).

- In principle, these regions can remain relatively intact and functional even when damage to the hippocampal formation is severe.

- Perirhinal cortex projects to the lateral region of the amygdala thought to be critical to fear conditioning (McDonald 1992, 1998).

An important implication of this analysis is that if these regions of the neocortex are damaged either prior to or after fear conditioning, contextual fear conditioning will be impaired. This is because these cortices would not be available to support a context representation and the hippocampal formation would be deprived of the information it needs to make its contribution to contextual fear. The literature supports this analysis (Corodimas and LeDoux 1995; Buffalo et al. 1999; Bucci et al. 2000, 2002). Note this pattern of results, damage to these regions both before and after training impairs contextual fear conditioning differs from that associated with damage to the hippocampal formation because contextual fear conditioning is spared if the hippocampal formation is damaged before conditioning.

The contribution of the entorhinal cortex to context representations that support fear conditioning also needs to be considered. The entorhinal cortex is to some extent a complex interface between PER and POR cortices and hippocampal formation. It receives input from these regions, and because of its intrinsic connections, it is positioned to further process and integrate this information before it is passed on to the various subregions of the hippocampal formation (van Strien et al. 2009). Given these anatomical relationships, one might also assume that damage to the entorhinal cortex will leave PER and POR cortices relatively intact. If so, then one might expect that damage to the entorhinal cortex should produce the same pattern of results as damage to the hippocampal formation. Damage to this region prior to conditioning should leave contextual fear conditioning intact, but damage after training should produce a significant impairment.

Consistent with this analysis, there are several reports that damage to the entorhinal cortex does not impair contextual fear conditioning (Phillips and LeDoux 1995; Good and Honey 1997; Bannerman et al. 1999). Maren et al. (1997), however, reported impairment. Recently, Keene and Bucci (2008), based on their report that damage to retrosplenial cortex impairs contextual fear, suggested that because Maren et al. (1997) used an axon-destroying lesion method, their result might in part be due to their lesion disrupting connections between retrosplenial cortex and POR. One study (Majchrzak et al. 2006) has reported conditions in which excitotoxic damage to the medial posterior region of entorhinal cortex influences contextual fear conditioning. It is not clear why their results differed from what others have reported. Unfortunately, there are no data available to evaluate the second prediction - that just as damage to hippocampal formation after conditioning impairs contextual fear conditioning, so should post-training damage to the entorhinal cortex.

In summary, the review of the contextual fear conditioning literature and accompanying analysis supports the basic premise that there are at least two neural systems that can support context representations needed for contextual fear conditioning. They are a hippocampal system composed of parahippocampal regionsPER, POR, and entorhinal cortices, and the hippocampal formation-and a neocortical system composed of the PER and POR cortices (see Fig. 5). When the hippocampal system is functioning, it limits the independent contribution of the neocortical system to contextual fear conditioning. However, as noted, this dominance can be overcome with multiple training sessions.

\section{The two systems are not equivalent}

A neocortical and hippocampal system each can provide a representation of context that can support contextual fear. However, as Biedenkapp and Rudy (2009) noted, other data derived from variations of the basic contextual fear-conditioning procedure and other paradigms indicate that these two systems do not provide equivalent support for the various ways in which context can function. The basis for such a conclusion is provided in the following sections.

\section{Context pre-exposure facilitation effect}

First, consider the context pre-exposure facilitation discovered by Fanselow (1990). The context pre-exposure facilitation effect clearly reveals that rats acquire a rich representation of an explored context. The literature surrounding this finding makes an important theoretical point (Rudy and O'Reilly 1999; Rudy et al. 2002; Matus-Amat et al. 2004). It confirms an implication of the

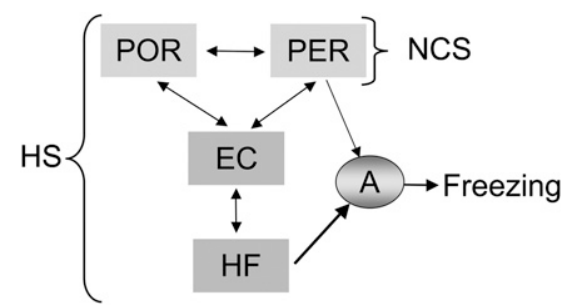

Figure 5. A highly schematic illustration of the neocortical and hippocampal systems (HS) that support context representations and their connections to the amygdala, which supports freezing. Note that PER and POR cortices can still support contextual fear even if the entorhinal cortex and hippocampal formation are damaged prior to conditioning. However, damage to PER and POR cortices prior to or after contextual fear conditioning deprive the animal of representations needed to support contextual fear. When the hippocampal system is intact, it tends to dominate the neocortical system in the competition for contextual control over fear, as indicated by the strength of the arrows connecting these regions to the amygdala. (NCS) Neocortical system; (HF) hippocampal formation; (EC) entorhinal cortex; (POR) postrhinal cortex; (PER) perirhinal cortex; (A) amygdala. 
hierarchical-representation view of context-that even though the individual is not concurrently registering all features that make up a context, exposure to just a subset is enough to activate a representational background that defines the place where another event (the shock) is experienced (Nadel and Willner 1980; Nadel et al. 1985).

This point is supported by two observations. First, Rudy and O'Reilly (1999) exposed rats to two distinct contexts. In the exposure phase, the rats were carried to each context in a distinct transport $(\mathrm{T})$ cage $(\mathrm{T} 1 \rightarrow$ context 1 and $\mathrm{T} 2 \rightarrow$ context 2$)$. Subsequently, rats were transported to one of the contexts (e.g., $\mathrm{T} 2 \rightarrow$ context 2 ) and immediately shocked. In this example, T2 should retrieve a memory representation of context 2 . Rats were tested for fear to both context 1 and context 2 . The level of freezing depended on which transport cage was used to carry the rats when they were shocked. In the second case, rats were preexposed to one context but received immediate shock in a different context. These rats subsequently displayed significantly more fear to the context that had been previously explored than to the context where they were actually shocked (Rudy et al. 2002). Both results reveal that the transport cage retrieved a memory representation of the explored context and that this memory representation was associated with the immediate shock.

The context pre-exposure effect can be said to depend on a process called "pattern completion"-a portion of the experience that originally established the memory trace can activate or replay the entire experience. Many theorists assume that the hippocampal formation supports pattern completion and this is how it makes a critical contribution to the episodic memory system (e.g., Marr 1971; Teyler and DiScenna 1986; Squire 1992; McClelland et al. 1995; Rudy et al. 2002; Matus-Amat et al. 2004; Teyler and Rudy 2007).

If so, then one might expect that the context pre-exposure facilitation effect should depend on the integrity of the hippocampal system. The neocortical system should not be able to support this effect. This prediction is borne out in the literature. Damage to the hippocampal formation prior to context exposure or inactivating the hippocampal formation either (1) prior to context exposure, (2) prior to immediate shock, or (3) prior to the test for contextual fear conditioning prevents the context preexposure facilitation effect (Rudy et al. 2002; Matus-Amat et al. 2004; Rudy and Matus-Amat 2005). The additional implication of these data is that even though the neocortical system can support contextual fear conditioning it does not provide a representation that can be retrieved by some partial set of cues.

\section{Generalized contextual fear conditioning}

Another difference between these two systems emerges when the rodents are tested for generalized contextual fear. For example, Antoniadis and McDonald (2000) reported that rats with damage to the hippocampal formation prior to conditioning display contextual fear conditioning, but compared to normal rats, they displayed more generalized fear-they had difficulty discriminating between the shocked context and another similar context. Similarly, Frankland et al. (1998) reported that mice with prior damage to the hippocampal formation have difficulty learning to discriminate between two contexts, one paired with shock and the other with no shock. These results suggest that compared to the neocortical system, the hippocampal system supports a representation that limits generalization.

The results provided by Lehmann et al. (2009), however, provide a caveat to this conclusion. As noted above, they exposed rats to multiple sessions of contextual fear conditioning. In one experiment, they also exposed these rats to a different context but did not shock them. Rats that subsequently received extensive damage to the hippocampal formation discriminated between the two contexts during the fear test as well as rats in the control condition. In another experiment, rats just received the multiple sessions of contextual fear conditioning and were then tested for fear in the conditioning context and for fear in a novel context. The rats that received damage to the hippocampal formation after the training phase displayed no more generalized fear to the novel context than did the controls.

Wang et al. (2009) have also reported that multiple contextual fear-conditioning sessions prior to hippocampal damage can prevent the tendency for lesioned mice to overgeneralize contextual fear. In their study, mice with post-training damage to the hippocampal formation discriminated the shocked context from the nonshocked context up to $42 \mathrm{~d}$ after training and did so as well as controls. However, as in previous reports when only a single session of training preceded damage to the hippocampal formation, mice failed to discriminate between a shocked context and a novel context, whereas mice in the control condition did make this discrimination.

Embedded in the Supplemental figures section of the Wang et al. (2009) report, however, are data that also confirm the idea that the context representation system supported by the neocortical system is not equivalent to that supported by the hippocampal formation. In the course of their experiment, they exposed the mice to several different test contexts. When retested on the original discrimination, the intact rats continued to respond differentially to the shocked versus nonshocked context. In contrast, mice with damage to the hippocampal formation were unable to maintain this discrimination. These data suggest that an intact hippocampal formation protects the original context representations from interference from subsequent similar events in a manner not afforded by just the neocortical system.

\section{Incidental context learning}

As noted earlier, when rats experience pairings of a CS and food US, they not only condition to the CS, they also learn where the conditioning occurred. This so-called incidental context learning provides additional evidence that the two systems that support context representations and functions are not equivalent. This is because rats that sustained prior damage to the hippocampal formation do not display incidental context learning; they respond equivalently to the CS whether tested in the original training context or in a different context (Honey and Good 1993; Good et al. 1998). Similarly, Holt and Maren (1999) found that the hippocampal formation is needed to demonstrate the context specificity of latent inhibition. Thus, the neocortical system does not appear to support this function.

\section{The context and object recognition puzzle}

With or without the hippocampal formation, rats can readily associate a context with an aversive experience such as shock. The story is somewhat different, however, for their memory for where an object was experienced. As noted, normal rats can recognize both an encountered object and where it was encountered (Dellu et al. 1997; Dix and Aggleton 1999) — they tend to treat a previously encountered object as if were novel when it is re-encountered in a different but familiar context. In contrast, rats with damage to the hippocampal formation can recognize a previously experienced object but do not appear to remember where the object was encountered (Mumby et al. 2002; Eacott and Norman 2004; Norman and Eacott 2005; Good et al. 2007). Thus, we have another difference between context representations supported by the hippocampal system and representations supported by the neocortical system.

These results and conclusions are puzzling. More to the point, given that rats with anterograde damage to the hippocampal formation can associate an explored context with shock, why 
do they not associate an explored context with an object? One can dismiss the possibility that the failure occurs because they lack a neural representation of the object. Many researchers believe that the perirhinal cortex provides the neural support for object recognition because (1) rats with damage to the hippocampal formation explore novel objects more than objects that have been experienced; and (2) removal of perirhinal cortex eliminates this behavior (Meunier et al. 1993; Mumby and Pinel 1994; Zhu et al. 1995a,b; Aggleton et al. 1997; Winters and Bussey 2005; Good et al. 2007).

Thus, if the rat has a neocortical system that can support representations of context features and representations of objects, then the problem must reside in the processes that link context features to objects. So what special processing does the hippocampal system afford that enables a representation of context to be linked to an experienced object? A reasonable answer is that it supports "pattern completion."

Consider this analysis of the object-in-context problem. Object representations are constructions-objects are composed of arbitrarily combined sets of features. A memory representation of an object thus requires some sort of binding of these features into a new unit that can be discriminated from representations of other objects. Moreover, objects themselves have no special biological significance that demands intense exploration. Since both constructing an object's representation and linking it to representations of the context features require strengthening connections among relatively undedicated cortical neurons, one might imagine that the connection between any particular context feature and the object representation might not be strong enough to retrieve the object representation.

As noted, one advantage of the hippocampal system is that it supports pattern completion. This means that once such a representation of a context is constructed, when the animal is in that context, the entire neocortical pattern of neural activity representing all context features could be kept active. To paraphrase Nadel et al. (1985), once such a coherent representation is established, even though the individual might register only a subset of context features at the time of the event, the event will be represented as experienced in that particular place (Nadel and Willner 1980; Nadel et al. 1985). This property might be valuable during acquisition when associations between context feature representations and the object are being established. This idea gains force when it is appreciated that when the rat is actually exploring the object, it is unlikely to directly attend to any particular feature or combination of features that make up the context. This would mean that without some mechanism to maintain a representation of context when the rat is exploring the feature, the pattern of neocortical activity representing context features would likely be in an off state at the time the object is sampled, thus weakening the opportunity for context-object association. Thus, the hippocampal-system-dependent pattern completion mechanism might be essential for animals to learn and remember where an object was explored. Moreover, during retrieval, pattern completion could keep the context representation active and thus participate in the retrieval of the object representation.

The situation for contextual fear conditioning is different. First, unlike an object, there is nothing arbitrary about shock or its biological significance. Consequently, shock activates a behavioral system (Bolles 1970; Blanchard et al. 1976; Fanselow 1991) designed to defend and protect the animal from danger. Moreover, there is a known neural circuit in the amygdala complex that supports this behavioral system (LeDoux 1994, 1995; Maren 2003; Phelps and LeDoux 2005; Davis 2006). In addition, fibers project from the PER/POR cortical regions that support context features of the brain into the amygdala-based neural system that supports learned fear (McDonald 1992, 1998). In some sense, the brain is constructed to learn where aversive events occur and has dedicated input lines from regions that support context feature representations to the amygdala. One would imagine that when potently stimulated by an aversive stimulus, this dedicated system would also be easily modified to support the associations needed to support fear. Thus, conditioning to context may be less dependent on pattern completion processes afforded by the hippocampal formation than would be the case for objects in context recognition.

In concluding this section, it may be important to note that object-in-context studies typically only expose the animal to a single session of training. Thus, we do not know if the neocortical system could support this function if more training were given.

\section{The ambiguity function: Conditional discriminations}

As noted, there is a substantial literature indicating that an important function of context is to disambiguate the meaning of particular events. In a conditional discrimination, the meaning of two cues, $\mathrm{C} 1$ and $\mathrm{C} 2$, depends on the context, $\mathrm{A}$ or $\mathrm{B}$, in which they are presented $(\mathrm{A}: \mathrm{C} 1+, \mathrm{C} 2-$ or $\mathrm{B}: \mathrm{C} 1-, \mathrm{C} 2+)$. It is important to appreciate that this is a logical description of the task. It does not capture the details of how the conditional discriminations have been implemented in the laboratory. This is important because how the problem is actually constructed appears to determine its dependency on the hippocampal system. It is useful to discriminate between two categories of implementation, termed here Type I and Type II.

\section{Conditional discrimination Type I}

Type I problems are implemented in an enclosed operant conditioning environment where rats learn to press a lever for food in a chamber typically enclosed in a sound-attenuating shell. Varying the stable visual, tactile, auditory, and olfactory features of the conditioning chambers can create two contexts. The discriminative cues might be the onset of a light or the onset of a tone. In context A the rat is rewarded for pressing the bar in the presence of the light and not rewarded when the tone is present. In context $\mathrm{B}$ the contingencies are reversed. It is important to note that this type of arrangement almost guarantees that the animal will experience the correct inputs from the context features, the cues, the response, and the outcomes. Rats with complete damage to the hippocampal formation learn these discriminations as readily as intact animals (McDonald et al. 1997; Good et al. 1998; Coutureau et al. 2002).

\section{Conditional discrimination Type II}

The form of the Type II problem is quite different. In this case, the problem is implemented by making the significance of the cues conditional upon where they are located in an open field (Sziklas and Petrides 2002; Dumont et al. 2007). As an example, consider a problem constructed by Dumont et al. (2007). Training occurred in a rectangular open field situated in a room with distinctive extramaze cues on the walls (see Fig. 6). Two cubes, one featuring a black rectangle and the other a white triangle, were presented side by side on each trial, and the animal could earn a reward by poking its head through a swinging door on the cube. Varying where the two cubes were located on each trial created the conditional nature of the problem. When at the north end of the open field, food was in the cube marked by the black rectangle, but when in the south end, the cube marked by the white triangle contained the food. At the start of a trial, the animal was released from the opposite end. So the extramaze cues at the north end provided the context in which the black rectangle located the reward, and the extramaze cues at the south end provided the context in which the white triangle signal located the reward. Note that in this situation the animal completely controlled what 


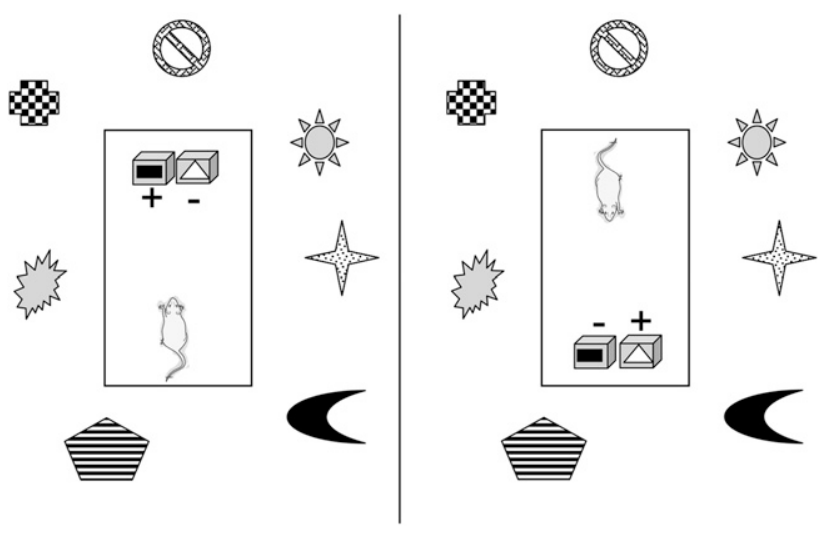

Figure 6. The Type II contextual conditional discrimination employed by Dumont et al. (2007). When the goal boxes are at one end of the rectangular platform, the box covered with the black rectangle is correct $(+)$ and the box covered with the white triangle is incorrect $(-)$. This contingency is reversed when the goal boxes are at the other end. The various features surrounding the platform represent distal cues. This problem, unlike the Type I problem, cannot be solved if the hippocampal formation is damaged.

features of the context or the cube were sampled and when the sampling occurred. Thus, there was nothing about this training arrangement that ensured the animal would experience the correct features of the context or cubes at the time the choice response was made. Rats with damage to the hippocampal formation were severely impaired on this type of problem.

The solution to Type II conditional discrimination poses the same general issue that was found in the context-object-recognition paradigm. Fundamentally, to solve the problem, the animal must have an active representation of the critical extramaze cues and choice stimuli at the time the choice behavior occurs in order for the outcomes to be correctly assigned to the choice stimuli. Thus, this problem also might depend on pattern completion processes afforded by the hippocampal system. With this type of representation, because of pattern completion, as the intact rat is approaching the choice stimuli, the representation of the surrounding environmental features would remain active even as it enters the cube. This would not be the case for the rat lacking a functional hippocampal formation; as the animal approaches the choice stimuli, only the representations of the features of the two cubes would be active, and they would be the same regardless of whether the cubes were in the north or south end of the arena.

If this analysis is correct, it should be possible to construct a conditional discrimination problem with the same cubes used by Sziklas and Petrides (2002) that does not depend on pattern completion and that would be solved by rats with damage to the hippocampal formation. For example, using the same rectangular area, one could create a conditional discrimination using two auditory cues, A1 and A2, to signal which cube is correct. By having this dominant cue there would be less need for pattern completion processes to keep the relevant representations active.

\section{The ambiguity function: Context-specific extinction}

As noted, when both conditioning and extinction have taken place, the CS can be considered ambiguous-the CS has been accompanied by the presentation of the US and by no US. Current theory holds that the CS is ambiguous because the animal associates the CS with the US (called a CS-US association) and also associates the CS with no US (called a CS-no US association). Contextual information can resolve this ambiguity because rats trained in context $\mathrm{A}$ and extinguished in context $\mathrm{B}$ will display a renewed conditioned response if they are retested in context $\mathrm{A}$ (the ABA design) or another context $\mathrm{C}$ (the $\mathrm{ABC}$ design). Bouton and colleagues (Wilson et al. 1995; Frohardt et al. 2000) were the first to examine the contribution of the hippocampal formation to context-specific extinction. Using the ABA design, they found no evidence that relatively complete damage to the hippocampal formation disrupted context-specific extinction.

In contrast to Bouton's findings, Maren and colleagues (Corcoran and Maren 2001, 2004; Corcoran et al. 2005; Ji and Maren 2005; Hobin et al. 2006) report that context-specific extinction does require a contribution of the hippocampal formation. For example, using both the $\mathrm{ABA}$ and $\mathrm{ABC}$ designs, Ji and Maren (2005) reported that electrolytic damage to just the dorsal hippocampus either prior to extinction per se or prior to the renewal test eliminated context-dependent extinction. Similar results have been obtained when the dorsal hippocampus is temporarily inactivated by muscimol (Corcoran and Maren 2004).

It is difficult to know just why the Bouton and Maren laboratories obtained such different results. However, the following analysis might provide some insight into the discrepancy. On the surface the context-specific extinction paradigm would have much in common with the Type I conditional discrimination procedure. Training occurred in an enclosed conditioning chamber that favored the animal jointly receiving context features and the CS. So, since rats with damage to the hippocampal formation can learn Type I problems, one might expect that they should also display context-dependent extinction-the result found by Bouton and colleagues (Wilson et al. 1995; Frohardt et al. 2000). There are many differences between the behavioral procedures used by the Bouton and Maren laboratories. However, there is one striking difference that may be important. Specifically, the dependent variable in Bouton's experiments was the change in the rate at which rats pressed a lever to receive a food reward when the $\mathrm{CS}$ was presented. By necessity, bar-press training requires that rats receive several hours of exposure to the training and test contexts, $\mathrm{A}$ and $\mathrm{B}$, prior to the beginning of the main conditioning part of the experiment. In contrast, the dependent variable in Maren's laboratory is the rat's freezing response. Consequently, rats in Maren's laboratory received much less exposure to the training and test contexts than did rats in Bouton's laboratory. It is possible that this extra exposure to the context puts the Bouton laboratory experiments closer to the Type I conditional discriminations than the limited context exposure that rats experienced in the Maren laboratory experiments. Thus, it may be that with extensive context exposure, the hippocampal formation is not needed to support context-specific extinction.

\section{Discussion}

More than 20 years ago, Nadel, Willner, and colleague (Nadel and Willner 1980; Nadel et al. 1985) proposed that there are at least two neural systems that can support context representations and functions. One system included the hippocampal formation, and a second system included neocortical regions outside of the hippocampal formation. They assumed that the hippocampal system supported the construction of a map-like representation of the co-occurring elemental features that define a context, and that once constructed and retrieved, this representation could be maintained in an active state and function as a coherent unit to provide context in which other experiences could be placed. The neocortical system, in contrast, only supported representations of the individual features, and a given feature was active only so long as it was the focus of attention.

This dual-system framework has proved to be remarkably prescient. It correctly anticipated the two most general conclusions that one can draw from the literature just discussed. First, context 
representations are supported by both a neocortical and a hippocampal system. This review suggests that context representations and functions are supported by a neocortical system composed of the PER and POR cortices and a hippocampal system composed of PER, POR, entorhinal cortex (EC), and the hippocampal formation.

Second, these two systems are not equivalent-not all context function can be supported by both systems. This review identified several context functions that the hippocampal system uniquely supports. They included: (1) the context pre-exposure effect; (2) limited generalized context fear (following singlesession training); (3) protection of established context representations from subsequent interference; (4) incidental learning of context; (5) object-in-context learning; (6) Type II context-dependent conditional discriminations; and (7) context-specific extinction (following limited context exposure).

This review also revealed several functions that can be supported by a neocortical system that remains when the hippocampal formation is damaged or inactivated. They include the support of contextual fear conditioning and Type 1 contextdependent conditional discriminations. When training is extensive, the number of context functions supported by the neocortical system increases. For example, with multiple training sessions, this system can also support context representations that limit generalized contextual fear and, if there is extensive exposure to the to-be-discriminated contexts, may support context-specific extinction.

\section{Canonical principles of hippocampal system function and context functions}

These findings to a large extent can be integrated by what might be called a set of canonical principles of hippocampal system function that emerged over the last $25 \mathrm{yr}$ to distinguish this system from other systems that can also support memory. O'Keefe and Nadel's (1978) classic multidimensional cognitive mapping theory of hippocampal formation provides one important set of ideas. They proposed that:

- At least two neural systems contribute to the storage and utilization of experience captured by the brain-a locale system supported by the hippocampal formation and a taxon system supported by a neural system that does not include the hippocampal formation. The idea that there are multiple neural systems that support learning in memory is now a foundation premise of the field.

- The hippocampal system is designed to automatically capture experience, unmotivated by intention to remember or by the need to solve a problem. Many theorists have embraced this attribute (Teyler and DiScenna 1986; Good et al. 1998; O'Reilly and Rudy 2001; Rudy et al. 2002; Day et al. 2003; Morris et al. 2003; Morris 2006; Teyler and Rudy 2007).

- The hippocampal system rapidly acquires information based on a single experience. This attribute also has been incorporated into many theories (e.g., Teyler and DiScenna 1986; McClelland et al. 1995; O'Reilly and Rudy 2001; Teyler and Rudy 2007).

- The hippocampal system supports the acquisition of information in the form of a map-like representation. Variations of this idea appear in many accounts as (1) a hippocampal index (Teyler and DiScenna 1986; Teyler and Rudy 2007); (2) configural representations (Sutherland and Rudy 1989); (3) a conjunctive representation (O'Reilly and Rudy 2001; Rudy and O'Reilly 2001; Rudy et al. 2002); and (4) a relational representation (Cohen and Eichenbaum 1993; Eichenbaum 1994). There are important differences between some of these views but they share the idea that the context representation supported by the hippocampal system is more than just the independent set of experienced coexperience features. It is the product of some sort of binding operation that links them into a coherent functional unit.

The complementary functions of pattern completion and pattern separation also need to be highlighted (Marr 1971; Teyler and DiScenna 1986; McNaughton and Morris 1987; McNaughton and Nadel 1990; McNaughton 1991; O'Reilly and McClelland 1994; O'Reilly and Rudy 2001). These ideas can be appreciated in relationship to Teyler and DiScenna's indexing theory, illustrated in Figure 7. The basic ideas captured in the indexing theory are that:

- The concurrent set of active neocortical patterns of neural activity produced by a particular experience projects to the hippocampal formation and activates a unique set of synapses.

- The memory for the experiences is stored as strengthened connections among those hippocampal synapses activated by the input pattern. This is the index. It stores a map of the concurrent neocortical inputs.

- Memory retrieval occurs because a subset of the initial input pattern can activate the hippocampal index. When this occurs, output from the hippocampal formation projects back to the neocortex to activate the entire pattern.

"Pattern separation" refers to the idea that the architecture of the hippocampal formation allows it to store representations of overlapping input patterns in a manner that minimizes the potential interference between them (for details, see O'Reilly and McClelland 1994; O'Reilly and Rudy 2001).

\section{Application}

One or more of these principles appear to be at the root of the list of context functions that require the hippocampal system. For example, the context pre-exposure effect depends on the pattern completion properties provided by the hippocampal formation, and it is likely that the learning is not motivated by the need to

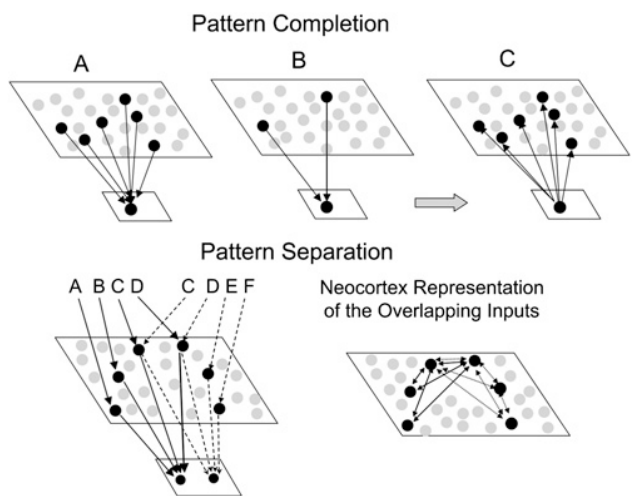

Figure 7. The pattern completion and pattern separation processes in the context of Teyler and DiScenna's (1986) indexing theory. Pattern completion: $(A)$ A set of neocortical patterns activated by a particular experience projects to the hippocampal formation and activates a unique set of synapses. The memory for the experiences is stored as strengthened connections among those hippocampal synapses activated by the input pattern (this is the index). (B) A subset of the initial input pattern can activate the index. (C) When this occurs, output from the hippocampal formation projects back to the neocortex to activate the entire pattern. Pattern separation: The hippocampal formation supports pattern separation by creating separate indices to similar input patterns. Note that two similar input patterns ( $A B C D$ and $C D E F)$ converge on different representational units in the lower level that represents the hippocampal formation. In contrast, these two patterns would not be separated in the neocortex, so it would have trouble keeping these patterns separated. 
obtain reward. Similarly, Type II compared to Type I contextual conditional discriminations arguably require the contribution of pattern completion (and likely pattern separation processes) to ensure that the correct representation of context is available when the animal makes the correct choice. Pattern completion processes also are likely to be important to learning the location of objects.

The importance of pattern separation to context functions is revealed in studies of generalized contextual fear following single training sessions (Frankland et al. 1998; Antoniadis and McDonald 2000). In such studies, rats with a damaged hippocampal formation generalize fear to other contexts more than the normal rat. Recent studies have revealed that this enhanced generalization can be normalized with extensive training before the hippocampal system is damaged (Lehmann et al. 2009). Yet, even in this case, representations established prior to damage to the hippocampal system are more vulnerable to interference from subsequent experiences with new contexts than is the case if the hippocampal system is intact (Wang et al. 2009). One might also wonder if the detailed neocortical context representations established with multiple training sessions benefited from the presence of the entire hippocampal systems. These studies should be repeated in animals that sustain damage to the hippocampal formation prior to multiple training sessions.

Several findings reveal that the hippocampal system supports incidental learning of context. Intact rats respond more to a CS tested in the training context than when tested in a different context and also display context-specific extinction following limited exposure to the context. However, these outcomes are eliminated by damage to the hippocampal formation or by inactivating it. In neither case is there any requirement that the animal construct a context representation to learn the Pavlovian contingency.

The neocortical system can support some context functions. This is especially the case when the context function requires extensive training to emerge and/or the solution to a problem requires integrating context features with other events occurring in that context. For example, Type I context conditional discriminations require extensive training to solve, and rats with damage to the hippocampal formation can solve them. Likewise, multiple sessions of contextual fear conditioning prior to training can establish neocortical representations that can be used to discriminate the training context from other contexts. Yet, as just noted, these representations are more vulnerable to interference than are context representations supported by the complete hippocampal system.

\section{Concluding comments}

Studies with animals have revealed many ways in which the hippocampal system is involved in context functions. One might argue that the most profound way in which it contributes is by providing support for pattern completion. One way to think about the importance of this process is to imagine what life would be with and without it. With this process available, once a coherent context representation is established, it remains active regardless of which particular features are currently attended. Pattern completion is happening all the time as we interact with our world. In contrast, without such a process, only representations of directly attended features will be in an active state. When a feature is no longer attended, its representation becomes inactive.

When I discussed these ideas with a prominent memory researcher, Professor Morris Moscovitch, he immediately brought up a supporting observation from his work with human amnesic patients. Specifically, he asked me to tell him what was behind me. I immediately gave the correct answer. He then noted that when he asked an amnesic, KC, the same question the answer was, "I don't know." Presumably this must be what it is like without the pattern completion process afforded by the hippocampal system. The representation of a current context consists only of the features attended at the moment. To the extent that our memories for the episodes that compose our personal history depend on embedding the experience in the context in which they occur, our connection with the past would obviously be quite limited if we were deprived of a neural system that can support pattern completion.

\section{Acknowledgments}

This work was supported by NIH RO1 MH61316 to J.W.R. I thank Julia A. Rudy for her editorial contribution to this paper.

\section{References}

Aggleton JP, Keen S, Warburton EC, Bussey TJ. 1997. Extensive cytotoxic lesions involving both the rhinal cortices and area TE impair recognition but spare spatial alternation in the rat. Brain Res 43: 279-287.

Antoniadis EA, McDonald RJ. 2000. Amygdala, hippocampus, and discrimination fear conditioning to context. Behav Brain Res 108: 1-19.

Ayres JJ, Bombace JC, Shurtleff D, Vigorito M. 1985. Conditioned suppression tests of the context-blocking hypothesis: Testing in the absence of the preconditioned context. J Exp Psychol Anim Behav Process 1: $1-14$.

Balsam PD, Tomie A. 1985. Context and learning. Erlbaum Associates, Hilldsale, NJ.

Bannerman DM, Yee BK, Good MA, Heupel MJ, Iversen SD, Rawlins JN. 1999. Double dissociation of function within the hippocampus: A comparison of dorsal, ventral, and complete hippocampal cytotoxic lesions. Behav Neurosci 113: 1170-1188.

Biedenkapp JC, Rudy JW. 2009. Hippocampal and extra-hippocampal systems compete for control of contextual fear: Role of ventral subiculum and amygdala. Learn Mem 16: 38-45.

Blanchard RJ, Fukunaga KK, Blanchard DC. 1976. Environmental control of defensive reactions to footshock. Bull Psychon Soc 8: 129-130.

Bolles RC. 1970. Species-specific defense reactions and avoidance learning. Psych Rev 79: 32-48.

Bouton ME. 1993. Context, time, and memory retrieval in the interference paradigms of Pavlovian learning. Psychol Bull 114: 80-99.

Bouton ME. 2004. Context and behavioral processes in extinction. Learn Mem 11: 485-494.

Bouton ME, Bolles RC. 1979. Contextual control of the extinction of conditioned fear. Learn Mot 10: 445-466.

Bucci DJ, Phillips RG, Burwell RD. 2000. Contributions of postrhinal and perirhinal cortex to contextual information processing. Behav Neurosci 114: $882-894$.

Bucci DJ, Saddoris MP, Burwell RD. 2002. Contextual fear discrimination is impaired by damage to the postrhinal or perirhinal cortex. Behav Neurosci 116: 479-488.

Buffalo EA, Ramus SJ, Clark RE, Teng E, Squire LR, Zola SM. 1999. Dissociation between the effects of damage to perirhinal cortex and area TE. Learn Mem 6: 572-599.

Burwell RD. 2000. The parahippocampal region: Corticocortical connectivity. Ann N Y Acad Sci 911: $25-42$.

Burwell RD, Amaral DG. 1998a. Perirhinal and postrhinal cortices of the rat: Interconnectivity and connections with the entorhinal cortex. J Comp Neurol 391: 293-321.

Burwell RD, Amaral DG. 1998b. Cortical afferents of the perirhinal, postrhinal, and entorhinal cortices of the rat. J Comp Neurol 398: $179-205$.

Cho YH, Friedman E, Silva AJ. 1999. Ibotenate lesions of the hippocampus impair spatial learning but not contextual fear conditioning in mice. Behav Brain Res 98: 77-87.

Cohen NJ, Eichenbaum H. 1993. Memory, amnesia and the hippocampal system. MIT Press, Cambridge, MA.

Corcoran KA, Maren S. 2001. Hippocampal inactivation disrupts contextual retrieval of fear memory after extinction. J Neurosci 21: 1720-1726.

Corcoran KA, Maren S. 2004. Factors regulating the effects of hippocampal inactivation on renewal of conditional fear after extinction. Learn Mem 11: $598-603$.

Corcoran KA, Desmond TJ, Frey KA, Maren S. 2005. Hippocampal inactivation disrupts the acquisition and contextual encoding of fear extinction. J Neurosci 23: 8978-8987. 
Corodimas KP, LeDoux JE. 1995. Disruptive effects of posttraining perirhinal cortex lesions on conditioned fear: Contributions of contextual cues. Behav Neurosci 109: 613-619.

Coutureau E, Killcross AS, Good M, Marshall VJ, Ward-Robinson J, Honey RC. 2002. Acquired equivalence and distinctiveness of cues: II. Neural manipulations and their implications. J Exp Psychol Anim Behav Process 28: 388-396.

Davis M. 2006. Neural systems involved in fear and anxiety measured with fear-potentiated startle. Am Psychol 61: 741-756.

Day MR, Langston R, Morris RG. 2003. Glutamate-receptor-mediated encoding and retrieval of paired-associate learning. Nature 424: 205-209.

Dellu F, Fauchey V, Le Moal M, Simon H. 1997. Extension of a new two-trial memory task in the rat: Influence of environmental context on recognition processes. Neurobiol Learn Mem 67: 112-120.

Dix SL, Aggleton JP. 1999. Extending the spontaneous preference test of recognition: Evidence of object-location and object-context recognition. Behav Brain Res 99: 191-200.

Dumont J, Petrides M, Sziklas V. 2007. Functional dissociation between fornix and hippocampus in spatial conditional learning. Hippocampus 17: 1170-1179.

Eacott MJ, Norman G. 2004. Integrated memory for object, place, and context in rats: A possible model of episodic-like memory? J Neurosci 24: 1948-1953.

Eichenbaum H. 1994. The hippocampal system and declarative memory in humans and animals: Experimental analysis and historical origins. In Memory systems (eds. DL Schacter and E Tulving), pp. 196-201. MIT Press, Cambridge, MA.

Eichenbaum H. 2000. A cortical-hippocampal system for declarative memory. Nat Rev Neurosci 1: 41-50.

Epp J, Keith JR, Spanswick SC, Stone JC, Prusky GT, Sutherland RJ. 2008. Retrograde amnesia for visual memories after hippocampal damage in rats. Learn Mem 15: 214-221.

Fanselow MS. 1990. Factors governing one trial contextual conditioning. Anim Learn Behav 18: 264-270.

Fanselow MS. 1991. The midbrain periacquiductal gray as coordinator of action in response to fear and anxiety. In The midbrain periacquiductal gray matter (eds. A Depaulis and R Bandler), pp. 151-171. Plenum Press, New York.

Frankland PW, Cestari V, Filipkowski RK, McDonald RJ, Silva AJ. 1998. The dorsal hippocampus is essential for context discrimination but not for contextual conditioning. Behav Neurosci 112: 863-874.

Frohardt RJ, Guarraci FA, Bouton ME. 2000. The effects of neurotoxic hippocampal lesions on two effects of context after fear extinction. Behav Neurosci 114: 227-240.

Furtak SC, Wei SM, Agster KL, Burwell RD. 2007. Functional neuroanatomy of the parahippocampal region in the rat: The perirhinal and postrhinal cortices. Hippocampus 17: 709-722.

Good M, Honey RC. 1997. Dissociable effects of selective lesions to hippocampal subsystems on exploratory behavior, contextual learning and spatial learning. Behav Neurosci 111: 487-493.

Good M, de Hoz L, Morris RG. 1998. Contingent versus incidental context processing during conditioning: Dissociation after excitotoxic hippocampal plus dentate gyrus lesions. Hippocampus 8: 147-159.

Good MA, Barnes P, Staal V, McGregor A, Honey RC. 2007. Context- but not familiarity-dependent forms of object recognition are impaired following excitotoxic hippocampal lesions in rats. Behav Neurosci 121: 218-223.

Hall G, Minor H. 1984. A search for context-stimulus associations in latent inhibition. Q J Exp Psychol B 36: 145-169.

Hirsh R. 1974. The hippocampus and contextual retrieval of information from memory: A theory. Behav Biol 12: 421-444.

Hirsh R. 1980. The hippocampus, conditional operations, and cognition. Physiol Psychol 8: 175-182.

Hobin J, Ji S, Maren S. 2006. Ventral hippocampal muscimol disrupts context-specific fear memory retrieval after extinction in rats. Hippocampus 16: 174-182.

Holt WG, Maren S. 1999. Muscimol inactivation of the dorsal hippocampus impairs contextual retrieval of fear memory. J Neurosci 19: 9054-9062.

Honey RC, Good M. 1993. Selective hippocampal lesions abolish the contextual specificity of latent inhibition and conditioning. Behav Neurosci 107: 23-33.

Ji J, Maren S. 2005. Electrolytic lesions of the dorsal hippocampus disrupt renewal of conditional fear after extinction. Learn Mem 12: 270-276.

Ji J, Maren S. 2007. Hippocampal involvement in contextual modulation of fear extinction. Hippocampus 17: 749-758.

Kamin L. 1969. Selective association and conditioning. In Fundamental issues in associative learning (eds. NJ Mackintosh and WK Honig), pp. 42-89. Dalhousie University Press, Halifax, Canada.

Keene CS, Bucci DJ. 2008. Contributions of the retrosplenial and posterior parietal cortices to cue-specific and contextual fear conditioning. Behav Neurosci 122: 89-97.
Lavenex P, Amaral DG. 2000. Hippocampal-neocortical interaction: A hierarchy of associativity. Hippocampus 10: $420-430$.

LeDoux JE. 1994. Emotion, memory and the brain. Sci Am 270: 50-57.

LeDoux JE. 1995. Emotion: Clues from the brain. Annu Rev Psychol 46: 209-235.

Lehmann H, Lacanilao S, Sutherland RJ. 2007. Complete or partial hippocampal damage produces equivalent retrograde amnesia for remote contextual fear memories. Eur J Neurosci 5: 1278-1286.

Lehmann H, Sparks FT, Spanswick SC, Hadikin C, McDonald RJ, Sutherland RJ. 2009. Making context memories independent of the hippocampus. Learn Mem 16: 417-420.

Lubow RE. 1973. Latent inhibition. Psychol Bull 79: 398-407.

Majchrzak M, Ferry B, Marchand AR, Herbeaux K, Seillier A, Barbelivien A. 2006. Entorhinal cortex lesions disrupt fear conditioning to background context but spare fear conditioning to a tone in the rat. Hippocampus 16: 114-124.

Maren S. 1999. Neurotoxic or electrolytic lesions of the ventral subiculum produce deficits in the acquisition and expression of Pavlovian fear conditioning in rats. Behav Neurosci 113: 283-290.

Maren S. 2003. The amygdala, synaptic plasticity, and fear memory. Ann N Y Acad Sci 985: 106-113.

Maren S, Aharonov G, Fanselow MS. 1997. Neurotoxic lesions of the dorsal hippocampus and Pavlovian fear conditioning in rats. Behav Brain Res 88: $261-274$

Marr D. 1971. Simple memory: A theory for archicortex. Philos Trans R Soc Lond B Biol Sci 262: 23-81.

Matus-Amat P, Higgins EA, Barrientos RM, Rudy JW. 2004. The role of the dorsal hippocampus in the acquisition and retrieval of context memory representations. J Neurosci 24: 2431-2439.

McClelland JL, McNaughton BL, O'Reilly RC. 1995. Why there are complementary learning systems in the hippocampus and neocortex: Insights from the successes and failures of connectionist models of learning and memory. Psychol Rev 102: 419-457.

McDonald AJ. 1992. Projection neurons of the basolateral amygdala: A correlative Golgi and retrograde tract tracing study. Brain Res Bull 28: $179-185$.

McDonald AJ. 1998. Cortical pathways to the mammalian amygdala. Prog Neurobiol 55: 257-332.

McDonald RJ, Murphy RA, Guarracip FA, Gortler JR, White NM, Baker AC. 1997. Systematic comparison of the effects of hippocampal and fornixfimbria lesions on acquisition of three configural discriminations. Hippocampus 7: 371-388.

McNaughton BL. 1991. Associative pattern completion in hippocampal circuits: New evidence and new questions. Brain Res Brain Res Rev 16: 193-220.

McNaughton BL, Morris RGM. 1987. Hippocampal synaptic enhancement and information storage within a distributed memory system. Trends Neurosci 10: 408-415.

McNaughton BL, Nadel L. 1990. Hebb-Marr networks and the neurobiological representation of action in space. In Neuroscience and connectionist theory (eds. MA Gluck and DE Rumelhart) pp. 1-65. Erlbaum, Hillsdale, NJ.

Medin DL, Reynolds TJ. 1985. Cue-context interactions in discrimination categorization and memory. In Context and learning (eds. PD Balsam and A Tomie) pp. 323-356. Erlbaum, Hilldsale, NJ.

Meunier M, Bachevalier J, Mishkin M, Murray EA. 1993. Effects on visual recognition of combined and separate ablations of the entorhinal and perirhinal cortex in rhesus monkeys. J Neurosci 13: 5418-5432.

Morris RGM. 2006. Elements of a neurobiological theory of hippocampal function: The role of synaptic plasticity, synaptic taggings and schemas. E J Neurosci 23: 2829-2846.

Morris RGM, Moser EI, Riedel G, Martin SI, Sandin J, Day M, O'Carroll C. 2003. Elements of a neurobiological theory of the hippocampus: The role of activity-dependent synaptic plasticity in memory. Phil Trans $R$ Soc London B Biol Sci 358: 773-786.

Mumby DG, Pinel JPJ. 1994. Rhinal cortex lesions and object recognition in rats. Behav Neurosci 108: 11-18.

Mumby DG, Gaskin S, Glenn MJ, Schramek TE, Lehmann H. 2002. Hippocampal damage and exploratory preferences in rats: Memory for objects, places, and contexts. Learn Mem 9: 49-57.

Nadel L. 2008. The hippocampus and context revisited. In Hippocampal place fields: Relevance to learning and memory (ed. SJY Mizumori), pp. 3-15. Oxford University Press, New York.

Nadel L, Moscovitch M. 1997. Memory consolidation, retrograde amnesia and the hippocampal complex. Curr Opin Neurobiol 17: 217-227.

Nadel L, Willner J. 1980. Context and conditioning: A place for space. Physiol Behav 8: 218-228.

Nadel L, Willner J, Kurz EM. 1985. Cognitive maps and environmental context. In Context and learning (eds. P Balsam and A Tomie), pp. 385-406. Erlbaum, Hillsdale, NJ. 
Norman G, Eacott MJ. 2005. Dissociable effects of lesions to he perirhinal cortex and the postrhinal cortex on memory for context and objects in rats. Behav Neurosci 119: 557-566.

O'Keefe J, Nadel L. 1978. The hippocampus as a cognitive map. Clarendon, Oxford, UK.

O'Reilly RC, McClelland JL. 1994. Hippocampal conjunctive encoding, storage, and recall: Avoiding a trade-off. Hippocampus 4: 661-682.

O'Reilly RC, Rudy JW. 2001. Conjunctive representations in learning and memory: Principles of cortical and hippocampal function. Psychol Rev 108: 311-345.

Penick S, Solomon PR. 1991. Hippocampus, context, and conditioning. Behav Neurosci 105: 611-617.

Phelps EA, LeDoux JE. 2005. Contributions of the amygdala to emotion processing: From animals models to human behavior. Neuron 48: $175-187$.

Randich A, Ross RT. 1985. Contextual stimuli mediate the effects of pre- and post-exposure to the unconditioned stimulus on condition suppress. In Context and learning (eds. PD Balsam and A Tomie), pp. 105-132. Erlbaum, Hillsdale, NJ.

Rescorla RA, Wagner AR. 1972. A theory of Pavlovian conditioning: Variations in the effectiveness of reinforcement and nonreinforcement. In Classical conditioning II: Current research and theory (eds. AH Black and WK Prokasy), pp. 64-99. Appleton-Century-Crofts, New York.

Richmond MA, Yee BK, Pouzet B, Veenman L, Rawlins JN, Feldon J, Bannerman DM. 1999. Dissociating context and space within the hippocampus: Effects of complete, dorsal, and ventral excitotoxic hippocampal lesions on conditioned freezing and spatial learning. Behav Neurosci 113: 1189-1203.

Rudy JW. 2008. The neurobiology of learning and memory. Sinauer, Sunderland, MA.

Rudy JW, Matus-Amat P. 2005. The ventral hippocampus supports a memory representation of context and contextual fear conditioning: Implications for a unitary function of the hippocampus. Behav Neurosci 119: $154-163$.

Rudy JW, Morledge P. 1994. Ontogeny of contextual fear conditioning in rats: Implications for consolidation, infantile amnesia, and hippocampal system function. Behav Neurosci 108: 1-8.

Rudy JW, O'Reilly RC. 1999. Contextual fear conditioning, conjunctive representations, pattern completion, and the hippocampus. Behav Neurosci 113: 867-880.

Rudy JW, O'Reilly RC. 2001. Conjunctive representations, the hippocampus, and contextual fear conditioning. Cogn Affect Behav Neurosci 1: 66-82.

Rudy JW, Wright Hardesty K. 2005. The temporal dynamics of a context memory: something is missing. Learn Mem 12: 172-177.

Rudy JW, Barrientos RM, O'Reilly RC. 2002. Hippocampal formation supports conditioning to memory of a context. Behav Neurosci 116: 530-538.

Sanders MJ, Wiltgen BJ, Fanselow MS. 2003. The place of the hippocampus in fear conditioning. Eur J Pharmacol 463: 217-223.

Smith DM, Mizumori SJ. 2006a. Hippocampal place cells, context, and episodic memory. Hippocampus 16: 716-729.

Smith DM, Mizumori SJ. 2006b. Learning-related development of contextspecific neuronal responses to places and events: The hippocampal role in context processing. J Neurosci 22: 3154-3163.
Squire LR. 1992. Memory and the hippocampus: A synthesis from findings with rats, monkeys, and humans. Psychol Rev 99: 195-231.

Squire LR, Kandel ER. 1999. Memory: From mind to molecules, p. 69. Freeman, New York.

Stote DL, Fanselow MS. 2004. NMDA receptor modulation of incidental learning in Pavlovian context conditioning. Behav Neurosci 118: 253-257.

Sutherland RS, Rudy JW. 1989. Configural association theory: The role of the hippocampus in learning, memory and amnesia. Psychobiology 17: 129-144.

Sutherland RJ, Weisend MP, Mumby D, Astur RS, Hanlon FM, Koerner A, Thomas MJ, Wu Y, Moses S, Cole C, et al. 2001. Retrograde amnesia after hippocampal damage: Recent vs. remote memories in two tasks. Hippocampus 11: 27-42.

Sutherland RJ, O'Brien J, Lehmann H. 2008. Absence of systems consolidation of fear memories after dorsal, ventral, or complete hippocampal damage. Hippocampus 18: 710-718.

Sziklas V, Petrides M. 2002. Effects of lesions to the hippocampus or the fornix on allocentric conditional associative learning in rats. Hippocampus 12: 543-550.

Teyler TJ, DiScenna P. 1986. The hippocampal memory indexing theory. Behav Neurosci 100: 147-154.

Teyler TJ, Rudy JW. 2007. The hippocampal indexing theory and episodic memory: Updating the index. Hippocampus 17: 1158-1169.

Thomas DR. 1985. Contextual stimulus control of operant responding in pigeons. In Context and learning (eds. PD Balsam and A Tomie), pp. 295-322. Erlbaum, Hillsdale, NJ.

Tulving E. 2002. Episodic memory: From mind to brain. Ann Rev Psych 53: $1-25$.

van Strien NM, Cappaert NLM, Witter MP. 2009. The anatomy of memory: An interactive overview of the parahippocampal-parahippocampal network. Nat Rev Neurosci 10: 272-282.

Wang SH, Teixeira AL, Wheeler AL, Frankland PF. 2009. The precision of remote context memories does not require the hippocampus. Nat Neurosci 12: 253-255.

Westbrook RF, Good AJ, Kiernan MJ. 1994. Effects of the interval between exposure to a novel environment and the occurrence of shock on the freezing response of rats. QJ Exp Psychol 47B: 427-436.

Wilson A, Brooks AC, Bouton ME. 1995. The role of the rat hippocampal system in several effects of context in extinction. Behav Neurosci 109: 828-836.

Wiltgen BJ, Sanders MJ, Anagnostaras SG, Sage JR, Fanselow MS. 2006. Context fear learning in the absence of the hippocampus. J Neurosci 26: 5484-5491.

Winters BD, Bussey TJ. 2005. Transient inactivation of perirhinal cortex disrupts encoding, retrieval, and consolidation of object recognition memory. J Neurosci 25: 52-61.

Wyrwicka W. 1956. Studies of motor conditioned reflexes. VI. On the effect of experimental situation upon the course of motor conditioned reflexes. Acta Biol Exp (Warsz) 17: 189-203.

Zhu XO, Brown MW, Aggleton JP. 1995a. Neuronal signalling of information important to visual recognition memory in rat rhinal and neighbouring cortices. Eur J Neurosci 7: 753-765.

Zhu XO, McCabe BJ, Aggleton JP, Brown MW. 1995b. Effects of the novelty or familiarity of visual stimuli on the expression of the immediate early gene c-fos in rat brain. Neurosci 69: 821-829. 


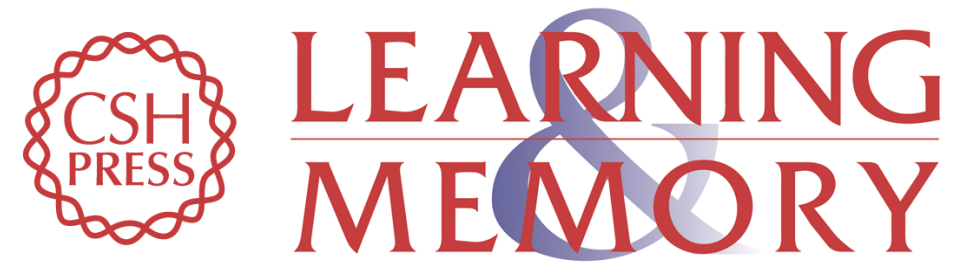

\section{Context representations, context functions, and the parahippocampal-hippocampal system}

Jerry W. Rudy

Learn. Mem. 2009, 16:

Access the most recent version at doi:10.1101//m.1494409

References This article cites 104 articles, 15 of which can be accessed free at:

http://learnmem.cshlp.org/content/16/10/573.full.html\#ref-list-1

License

Email Alerting Receive free email alerts when new articles cite this article - sign up in the box at the Service top right corner of the article or click here. 